\title{
Assessing ABO/Rh Blood Group Frequency and Association with Asymptomatic Malaria among Blood Donors Attending Arba Minch Blood Bank, South Ethiopia
}

\author{
Getaneh Alemu and Mohammedaman Mama \\ Department of Medical Laboratory Science, Arba Minch University, P.O. Box 21, Arba Minch, Ethiopia \\ Correspondence should be addressed to Getaneh Alemu; getanehmlt@gmail.com
}

Received 16 October 2015; Accepted 31 December 2015

Academic Editor: Kwadwo Koram

Copyright (C) 2016 G. Alemu and M. Mama. This is an open access article distributed under the Creative Commons Attribution License, which permits unrestricted use, distribution, and reproduction in any medium, provided the original work is properly cited.

\begin{abstract}
Background. Determination of the various $\mathrm{ABO} / \mathrm{Rh}$ blood group distributions and their association with malaria infection has paramount importance in the context of transfusion medicine and malaria control. Methods. Facility based cross-sectional study was conducted from February to June, 2015, to assess ABO/Rh blood groups distribution and their association with asymptomatic malaria. A structured questionnaire was used to collect data. Blood grouping was done using monoclonal antibodies. Thin and thick blood films were examined for Plasmodium parasites. Data were analyzed using SPSS version 20.0. Results. A total of 416 blood donors participated with median age of $22 \pm 0.29$ (median \pm standard error of the mean). Distribution of ABO phenotypes, in decreasing order, was $\mathrm{O}(175,42.1 \%), \mathrm{A}(136,32.7 \%), \mathrm{B}(87,20.9 \%)$, and $\mathrm{AB}(18,4.3 \%)$. Most of them were Rh+ (386, 92.8\%). The overall malaria prevalence was $4.1 \%(17 / 416)$. ABO blood group is significantly associated with malaria infection $(P=0.022)$. High rate of parasitemia was seen in blood group $\mathrm{O}$ donors $(6.899, P=0.003)$ compared to those with other ABO blood groups. Conclusion. Blood groups $\mathrm{O}$ and $\mathrm{AB}$ phenotypes are the most and the least $\mathrm{ABO}$ blood groups, respectively. There is significant association between $\mathrm{ABO}$ blood group and asymptomatic malaria parasitemia.
\end{abstract}

\section{Background}

The ABO blood group was the first human blood group discovered in 1901 by Landsteiner followed by Rh blood group in 1941 [1, 2]. Currently more than 30 blood groups have been described by the International Society of Blood Transfusion of which only $\mathrm{ABO}$ and $\mathrm{Rh}$ blood groups remain clinically most important $[3,4]$. The ABO blood grouping system consists of the $\mathrm{A}, \mathrm{B}$, and $\mathrm{H}$ carbohydrate antigens and antibodies against these antigens, while that of $\mathrm{Rh}$ is composed of $\mathrm{D}$ antigen [5]. Therefore ABO blood grouping is based on the presence or absence of $A$ and $B$ antigens on the surface of red blood cells (RBCs) and Rh grouping is based on the D antigen presence or absence on the RBC surface $[6,7]$. The blood group antigens are composed of genetically controlled glycoprotein and glycolipids [7]. All blood group systems are inherited and shared by all human populations but the frequency varies. Those variations depend on the alleles' distribution, mating system of a population, socioeconomic status, ethnic group, and race [8-10].

Since the Second World War, blood and blood component transfusion have been used to correct severe anemia, deficiency of plasma clotting factors, thrombocytopenia, immunodeficiency states, hypoalbuminaemia, and problems related to electrolytes [11, 12]. Transfusion of compatible blood at least for $\mathrm{ABO}$ and $\mathrm{Rh}$ antigens reduces transfusion reaction in recipients. The $\mathrm{ABO}$ and $\mathrm{Rh}$ blood groups are also useful in clinical studies, population genetic studies, and researching population migration patterns as well as resolving certain medicolegal issues, particularly of disputed paternity cases [13]. Therefore knowledge of the $\mathrm{ABO}$ and $\mathrm{Rh}$ blood group distribution in specific population has paramount importance in the context of transfusion medicine. Many previous studies in sub-Saharan Africa reported that blood group O and $\mathrm{Rh}+$ are the most frequent $\mathrm{ABO}$ and $\mathrm{Rh}$ blood groups, respectively, but the proportion varies by location $[5,14-16]$. 
Ilozumba and Uzozie [17] reported ABO blood group prevalence of $2.63 \%, 12.05 \%, 21.05 \%$, and $63.83 \%$ for groups $\mathrm{AB}, \mathrm{B}, \mathrm{A}$, and $\mathrm{O}$, respectively. In another study, Sirina and Clement [16] have reported prevalence of $3.2 \%, 18.52 \%$, $20.82 \%$, and $57.44 \%$ for groups AB, B, A, and O, respectively. Oladeinde et al. [18] also reported that blood groups O (57\%) and $\mathrm{AB}(3.2 \%)$ are with the highest and lowest distribution in Benin City of Nigeria. The distribution of ABO blood groups was O (46\%), A (27.1\%), B (23.1\%), and AB (3.8\%) according to a study by $\mathrm{H}$. Tadesse and $\mathrm{K}$. Tadesse, in northwest Ethiopia [5]. Similar study in West Gojam, Ethiopia [7], showed frequency distributions of $60 \%, 26 \%$, and $14 \%$ for blood groups of $\mathrm{O}, \mathrm{A}$, and $\mathrm{B}$, respectively. $\mathrm{Rh}+$ blood group distribution is much higher than $\mathrm{Rh}-$ in Africa according to previous reports $[5,7,16,18]$.

On the other side, both $\mathrm{ABO}$ and $\mathrm{Rh}$ blood groups have attracted enormous attention regarding their association with genetic and infectious diseases [9]. Previous studies on patients of cancer and tumor [19], heart diseases [20], and parasitic and viral infections [21] indicated associations of $\mathrm{ABO}$ and $\mathrm{Rh}$ blood groups. In particular, the $\mathrm{ABO}$ antigens regulate cellular activities suggesting their impact on determining susceptibility and severity of certain diseases [22]. It has been more than four decades since association of ABO blood group and malaria was suggested. There is also a hypothesis that Plasmodium falciparum (P. falciparum) malaria has shaped the distribution of $\mathrm{ABO}$ blood groups in humans [23]. Otajevwo [15] and Singh et al. [24] reported significant association between malaria and $\mathrm{ABO}$ blood groups where blood group $\mathrm{O}$ individuals are more susceptible than other $\mathrm{ABO}$ blood groups. However blood group $\mathrm{AB}$ individuals were more affected by malaria according to studies by Ilozumba and Uzozie [17] and Oche and Aminu [25]. Regarding disease severity, H. Tadesse and K. Tadesse [5] showed that being of blood group $\mathrm{O}$ protects from severe malaria. On the contrary, Sirina and Clement [16], Oladeinde et al. [18], and Epidi et al. [14] indicated that there is no significant association between $\mathrm{ABO}$ blood group and malaria parasitemia.

Many other coexisting factors made the study of relationship between malaria and $\mathrm{ABO} / \mathrm{Rh}$ blood groups difficult that varying findings are reported. Complexity of the interaction between the parasites and host immune responses as well as impact of other RBC polymorphisms may be responsible for such differences $[24,26-30]$. Hence the aim of the present study was to assess the $\mathrm{ABO} / \mathrm{Rh}$ blood group distribution and association with asymptomatic malaria among blood donors attending Arba Minch Blood Bank, South Ethiopia, where malaria is one of the most important public health problems.

\section{Materials and Methods}

2.1. Study Design and Area. Facility based cross-sectional study was conducted in Arba Minch Blood Bank from February to June 2015. Arba Minch is located $454 \mathrm{kms}$ south of Addis Ababa, the capital city of Ethiopia. It is found at an altitude of 1200-1300 meters above sea level with an average annual temperature of $29.7^{\circ} \mathrm{C}$ and rain fall of $900 \mathrm{~mm}$ [31].
Arba Minch town and the rural surroundings are one of the most malaria endemic areas of Ethiopia. Arba Minch Blood Bank, located in Arba Minch, is one of the three blood banks found in Southern Nation's, Nationalities, and Peoples Region (SNNPR) of Ethiopia. The blood bank works with an ultimate goal of immediate supply of safe blood for patients who need transfusion and, at average, collects 375 units of blood per month from voluntary donors.

2.2. Sample Size and Sampling Technique. All adult population with eligible age range (17-65 years old) for blood donation and living in malaria endemic catchment areas of Arba Minch blood bank were the source population. The study subjects were recruited from those who came to donate blood during the study period. The sample size was determined using single population proportion formula $(n=$ $\left.[Z 1-\alpha / 2]^{2} P(1-p) / d^{2}\right)$ at $95 \%$ confidence level $(Z(1-$ $\alpha / 2)=1.96)$. A $5 \%$ marginal error $(d)$ was tolerated and a proportion $(p)$ of 0.5 was assumed. Substituting the values, calculated sample size was 384 and the final sample size was 423 after adding $10 \%$ to compensate for nonrespondents. Systematic random sampling technique was followed. By tracing back last year's donor flow, we expected 1650 donors during the study period. Therefore, calculated $K$ value was 4 (1650/423). The first subject was selected by lottery method and then every fourth voluntary donor has been recruited. The inclusion criterion was passing the clinical screening criteria of the blood bank.

\subsection{Data Collection}

2.3.1. Sociodemographic Data. Nurses who are fluent speakers in the local language were selected and trained for data collection. Sociodemographic data was collected using a pretested structured questionnaire administered through face to face interview. The questionnaire was developed in order to capture data on sociodemographic characteristics, history of malaria, and previous blood donations.

2.3.2. Laboratory Methods. Five milliliters of venous blood was collected from each study participant for $\mathrm{ABO} / \mathrm{Rh}$ blood grouping and blood film preparation. $\mathrm{ABO}$ and $\mathrm{Rh}$ blood grouping was done using commercially prepared monoclonal anti-A, anti-B, and anti-D antisera (Agappe Diagnostics Ltd., India) following methods described by Cheesbrough [32]. The rapid forward (cell) grouping method was used. To determine malaria parasitemia, both thin and thick blood films were prepared and examined after staining with $10 \%$ Giemsa for 15 minutes. The thin film was fixed with absolute methanol $(96 \% \mathrm{v} / \mathrm{v})$ before staining. For positive samples, asexual stages of malaria parasites were counted against 500 white blood cells (WBC) on the thick film and reported as number of parasites per $\mu \mathrm{L}$ of blood assuming a standard adult leukocyte count of $8000 / \mu \mathrm{L}$. All laboratory procedures were processed in Arba Minch Blood Bank laboratory by well experienced and trained laboratory technologists following standard procedures. 
2.4. Statistical Analysis. Data were entered and analysed using statistical package for social sciences (SPSS) version 20.0. Descriptive statistics like frequency, median, and percentage were used to describe the study population characteristics. Bivariate logistic regression was used for assessment of general associations between categorical variables. Multiple logistic regression analysis then followed for variables with $P \leq 0.25$ in the bivariate analysis. Associations between variables were considered statistically significant only if $P$ value $\leq 0.05$ at $95 \%$ confidence level.

2.5. Data Quality Control. Data collectors were trained on the study procedures. The questionnaire was translated to the local language and retranslated back to English. Investigators supervised all aspects of data collection. Standard operating procedures were strictly followed for blood grouping and malaria diagnosis. Giemsa stalk solution was stored appropriately and the staining quality was checked every week by processing known positive and negative samples. All malaria positive and $10 \%$ of negative slides were blindly reexamined by another technologist and all blood groupings were done in duplicate. A maximum of $5 \%$ discordant readings were tolerated for malaria diagnosis and a third test (tie-breaker) was conducted during blood grouping in case the duplicate test results are discordant.

2.6. Ethical Clearance. Ethical approval for the research was granted by review boards of Arba Minch University College of Medicine and Health Sciences and Arba Minch Blood Bank. Written consent was obtained from all participating blood donors. All laboratory results were communicated to study subjects promptly.

\section{Results}

A total of 416 blood donors participated in the study with response rate of $98.3 \%$. Of the participants, 232 (55.8\%) were male and $184(44.2 \%)$ were female. The median age of the study subjects was $22 \pm 0.29$ (median \pm SEM) with a range of 18-59 years. Donors with self-reported malaria history account for 154 (37\%). Only 152 (36.5\%) donors sleep under bed net. All of the study subjects were voluntary donors and $219(52.6 \%)$ have donated blood before, while the rest 197 (47.4\%) came to donate blood for the first time. The most frequent $\mathrm{ABO}$ blood group was blood group O, 175 (42.1\%), followed by group A accounting for 136 (32.7\%) of the study subjects. Blood groups B and AB account for 87 (20.9\%) and $18(4.3 \%)$ of the donors, respectively. Most of the donors, 386 (92.8\%), were $\mathrm{Rh}+$, while only 30 (7.2\%) were Rh- (Table 1$)$. The distribution of various blood groups in relation to sex is summarized in Table 2. Blood groups $\mathrm{O}$ and $\mathrm{AB}$ are the highest and least distributed ones, respectively, both in males and females. Difference in the occurrence of ABO blood group phenotypes was not statistically significant between male and female donors $(P=0.656)$.

The overall malaria prevalence in the present study was 4.1\% (17/416). Eight and 9 donors were infected with $P$. falciparum and Plasmodium vivax (P. vivax), respectively.
TABLE 1: Sociodemographic characteristics and clinical history of blood donors attending Arba Minch Blood Bank from February to June 2015.

\begin{tabular}{|c|c|c|}
\hline \multirow{2}{*}{ Variables } & \multicolumn{2}{|c|}{ Frequency } \\
\hline & Number $(n)$ & Percent (\%) \\
\hline \multicolumn{3}{|l|}{ Sex } \\
\hline Male & 232 & 55.8 \\
\hline Female & 184 & 44.2 \\
\hline \multicolumn{3}{|l|}{ Age group } \\
\hline $18-27$ & 355 & 85.3 \\
\hline $28-37$ & 48 & 11.6 \\
\hline$>37$ & 13 & 3.1 \\
\hline \multicolumn{3}{|l|}{ Marital status } \\
\hline Single & 339 & 81.5 \\
\hline Married & 77 & 18.5 \\
\hline Total & 416 & 100 \\
\hline \multicolumn{3}{|l|}{ Educational level } \\
\hline Illiterate & 112 & 26.9 \\
\hline Primary & 21 & 5.0 \\
\hline Secondary & 76 & 18.3 \\
\hline Tertiary & 207 & 49.8 \\
\hline \multicolumn{3}{|l|}{ Occupation } \\
\hline House wife & 14 & 3.3 \\
\hline Peasant/agriculture & 117 & 28.1 \\
\hline Employed & 141 & 33.9 \\
\hline Business/shop & 79 & 19.1 \\
\hline Student & 65 & 15.6 \\
\hline \multicolumn{3}{|l|}{ Previous malaria infection } \\
\hline Yes & 154 & 37 \\
\hline No & 262 & 63 \\
\hline \multicolumn{3}{|l|}{ Time of last malaria episode } \\
\hline 2-6 months & 18 & 11.7 \\
\hline$>6$ months & 84 & 54.5 \\
\hline Do not remember the time & 52 & 33.8 \\
\hline \multicolumn{3}{|l|}{ Use of bed net the previous night } \\
\hline Yes & 152 & 36.5 \\
\hline No & 264 & 63.5 \\
\hline \multicolumn{3}{|c|}{ Previous history of blood donation } \\
\hline Yes & 219 & 52.6 \\
\hline No & 197 & 47.4 \\
\hline \multicolumn{3}{|l|}{ Number of previous donations } \\
\hline Once & 124 & 56.6 \\
\hline $2-4$ times & 78 & 35.6 \\
\hline$>4$ times & 17 & 7.8 \\
\hline \multicolumn{3}{|l|}{ ABO blood group } \\
\hline $\mathrm{O}$ & 175 & 42.1 \\
\hline $\mathrm{A}$ & 136 & 32.7 \\
\hline $\mathrm{B}$ & 87 & 20.9 \\
\hline $\mathrm{AB}$ & 18 & 4.3 \\
\hline \multicolumn{3}{|l|}{ Rh blood group } \\
\hline $\mathrm{Rh}+$ & 386 & 92.8 \\
\hline $\mathrm{Rh}-$ & 30 & 7.2 \\
\hline
\end{tabular}

Mixed infection was not detected. As can be seen from Table 3, most of malaria infected donors were with low parasitemia (light infection). Higher proportion of females 
TABLE 2: Phenotypic distribution of ABO blood group among blood donors attending Arba Minch Blood Bank from February to June 2015.

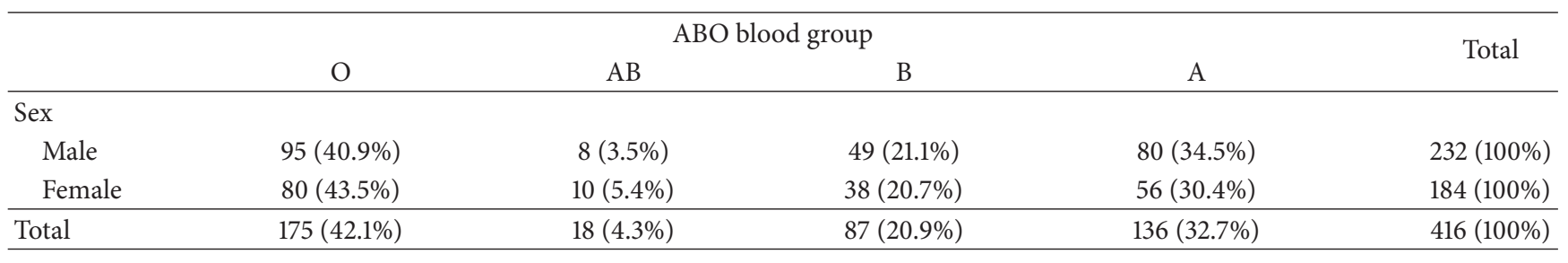

TABLE 3: Malaria prevalence and mean parasite load among ABO blood group phenotypes of blood donors attending Arba Minch Blood Bank from February to June 2015.

\begin{tabular}{lcccc}
\hline & Examined & Infected & Mean parasite density/ $\mu \mathrm{L}$ \\
\hline ABO blood group & & P. falciparum & P. vivax & \\
O & 175 & $5(2.6 \%)$ & $9(5.1 \%)$ & 377.14 \\
$\mathrm{AB}$ & 18 & $1(5.6 \%)$ & 0 & 320.0 \\
$\mathrm{~B}$ & 87 & $1(1.1 \%)$ & 0 & 320.0 \\
$\mathrm{~A}$ & 136 & $1(0.7 \%)$ & 0 & 80.0 \\
\hline Total & 416 & $8(1.9 \%)$ & $9(2.2 \%)$ & \\
\hline
\end{tabular}

$(6.0 \%, 11 / 183)$ were infected than males $(2.6 \%, 6 / 233)$ but the difference was not statistically significant $(P=0.091)$.

Bivariate analysis shows that malaria parasitemia was significantly associated with bed net utilization $(P=0.047)$, previous blood donation history $(P=0.022)$, and $\mathrm{ABO}$ blood group $(P=0.033)$ but according to logistic regression analysis, only $\mathrm{ABO}$ blood group $(P=0.022)$ is associated with malaria parasitemia. High rate of parasitemia was seen in blood group $\mathrm{O}$ donors $(8 \%, 14 / 175)$ followed by those having blood group $\mathrm{AB}(5.6 \%, 1 / 18)$. Malaria parasitemia was not significantly associated with $\mathrm{Rh}$ blood group $(P=0.104)$ (Table 4). ABO blood group was not significantly associated with both plasmodium species $(P=0.251)$ and parasite load $(P=0.976)$.

\section{Discussion}

The malaria prevalence $(4.1 \%)$ in the present study, which is a reflection of high rate of asymptomatic plasmodium parasitemia in endemic areas, seems considerable. Its implication is enormous when viewed from the recipients' side which are already weakened by existing severe diseases. The prevalence would even be much higher if the data was collected during the major malaria transmission season (September to December). Submicroscopic parasitemia is also common in asymptomatic carriers such that use of more sensitive diagnostic tests would yield higher rate of malaria infection. This is evidenced by findings from Ghana that a prevalence of $4.7 \%$ by microscopy increased to $18 \%$ when diagnosed using polymerase chain reaction [33].

In this study, high percentage of blood group O (42.1\%) phenotype was observed among study participants followed by A (32.7\%), B (20.9\%), and AB (4.3\%). This goes in line with some recent studies reporting high group $\mathrm{O}$ frequency in malaria rampant tropical regions as compared to group $\mathrm{A}[5$, $7,14,16-18]$. Studies in malaria free cold regions showed that group A phenotype is more common than $\mathrm{O}[34,35]$. Hence findings in the present study substantiate the hypothesis that $P$. falciparum has evolutionarily shaped the distribution of ABO phenotype. Other studies in malarious areas of India [36] show that B phenotype is the most abundant ABO blood group suggesting that the above scenario is not exclusive.

We found statistically significant association $(P=0.022)$ between $\mathrm{ABO}$ blood group and malaria parasitemia such that donors with blood group $\mathrm{O}$ had the predominant rate of infection $(8.0 \%, 14 / 175)$. Blood group $\mathrm{O}$ donors were 6.899 (95\% CI $=1.951-24.391 ; P=0.003$ ) times more susceptible to plasmodium infection than those with other ABO blood groups. This goes in line with findings from previous studies conducted in Nigeria [14, 15]. Contrasting results have been reported in other two studies in Nigeria, where $37.5 \%$ and $100 \%$ of the cases were with blood group $\mathrm{AB}[17,25]$. According to studies by Sirina and Clement [16], Otajevwo [15], and Oladeinde et al. [18], ABO blood groups were not significantly associated with malaria infection rate. Complexity of the interaction between the parasites and host immune responses as well as impact of other RBC polymorphisms may be responsible for such differences.

All four $\mathrm{ABO}$ phenotypes were infected with P. falciparum but only group $\mathrm{O}$ donors were parasitemic for $P$. vivax. This agrees with previous reports suggesting that individuals with blood groups A, B, and AB are more susceptible to $P$. falciparum infection than those with $\mathrm{O}$ phenotype [37]. Previous reports suggest that non-O-blood groups are associated with complicated or severe malaria because they confer resetting $[5,37]$. All infected participants were at the same level of morbidity (asymptomatic) and with comparable parasite load (light infection). Because of this, we could not assess the relation between $\mathrm{ABO}$ blood groups and malaria disease severity.

Most of the study participants were $\mathrm{Rh}+(92.8 \%)$ in this study which goes in line with previous studies $[5,16,38]$. 
TABLE 4: Association of malaria parasitemia with different independent variables among blood donors attending Arba Minch Blood Bank from February to June 2015.

\begin{tabular}{|c|c|c|c|c|c|c|}
\hline Variable & $\begin{array}{c}\text { Number } \\
\text { examined }\end{array}$ & $\begin{array}{c}\text { Rate of malaria } \\
\text { infection (\%) }\end{array}$ & Crude OR & $P$ value & Adjusted OR & $P$ value \\
\hline \multicolumn{7}{|l|}{ Sex } \\
\hline Male & 232 & $6(2.6 \%)$ & & & & \\
\hline Female & 184 & $11(6.0 \%)$ & $2.395(0.869-6.604)$ & 0.091 & $2.599(0.889-7.594)$ & 0.081 \\
\hline \multicolumn{7}{|l|}{ Age } \\
\hline $18-27$ & 355 & $15(4.2 \%)$ & & & & \\
\hline $28-37$ & 48 & $1(2.1 \%)$ & $0.482(0.062-3.735)$ & 0.640 & & \\
\hline$>37$ & 13 & $1(8.3 \%)$ & $1.889(0.230-15.495)$ & & & \\
\hline \multicolumn{7}{|l|}{ Educational status } \\
\hline Illiterate & 111 & $4(3.6 \%)$ & $0.73(0.224-2.382)$ & 0.853 & & \\
\hline Primary & 21 & $1(4.8 \%)$ & $0.985(0.12-8.096)$ & & & \\
\hline Secondary & 75 & $2(2.7 \%)$ & $0.532(0.114-2.487)$ & & & \\
\hline Tertiary & 209 & $10(4.8 \%)$ & & & & \\
\hline \multicolumn{7}{|l|}{ Occupation } \\
\hline House wife & 14 & $1(7.1 \%)$ & $5.346(0.454-63.005)$ & 0.450 & & \\
\hline Peasant/agriculture & 117 & $6(5.1 \%)$ & $3.757(0.744-18.976)$ & & & \\
\hline Employed & 141 & $2(1.4 \%)$ & & & & \\
\hline Business/shop & 79 & $5(6.3 \%)$ & $4.696(0.889-24.794)$ & & & \\
\hline Student & 65 & $3(4.6 \%)$ & $3.363(0.548-20.632)$ & & & \\
\hline \multicolumn{7}{|c|}{ Previous malaria infection } \\
\hline Yes & 155 & $6(3.9 \%)$ & $1.081(0.392-2.984)$ & 0.880 & & \\
\hline No & 261 & $11(4.2 \%)$ & & & & \\
\hline \multicolumn{7}{|l|}{ Use of bed net } \\
\hline Yes & 152 & $1(0.7 \%)$ & & & & \\
\hline No & 264 & $16(5.8 \%)$ & $4.518(1.019-20.032)$ & 0.047 & $3.990(0.866-18.384)$ & 0.076 \\
\hline \multicolumn{7}{|l|}{ ABO blood type } \\
\hline A & 136 & $1(0.7 \%)$ & $0.126(0.008-2.107)$ & 0.033 & $0.163(0.009-2.896)$ & 0.022 \\
\hline B & 87 & $1(1.1 \%)$ & $0.198(0.012-3.317)$ & & $0.292(0.016-5.235)$ & \\
\hline $\mathrm{AB}$ & 18 & $1(5.6 \%)$ & & & & \\
\hline $\mathrm{O}$ & 175 & $14(8.0 \%)$ & $1.478(0.183-11.945)$ & & $2.373(0.266-21.195)$ & \\
\hline \multicolumn{7}{|l|}{ Rh blood type } \\
\hline $\mathrm{Rh}+$ & 386 & $14(3.6 \%)$ & & & & \\
\hline $\mathrm{Rh}-$ & 30 & $3(10 \%)$ & $2.952(0.799-10.906)$ & 0.104 & $2.683(0.624-11.543)$ & 0.185 \\
\hline \multicolumn{7}{|c|}{ Previous history of blood donation } \\
\hline Yes & 219 & $4(1.8 \%)$ & & & & \\
\hline No & 197 & $13(6.6 \%)$ & $3.798(1.217-11.848)$ & 0.022 & $3.205(0.973-10.560)$ & 0.056 \\
\hline
\end{tabular}

The number of $\mathrm{Rh}+$ participants would be increased if weak$\mathrm{D}$ antigen was detected. Out of $30 \mathrm{Rh}-$ participants, 16 were female that occurrence of hemolytic disease of the new born may be a medical issue in the population. Similarly with previous studies $[5,14,22,39]$, $\mathrm{Rh}$ blood group is not associated with asymptomatic malaria infection in the present study.

\section{Conclusion}

Blood groups $\mathrm{O}$ and $\mathrm{AB}$ phenotypes are the most and the least frequent $\mathrm{ABO}$ blood groups, respectively, in the study population. There is considerable prevalence of malaria parasites in apparently healthy blood donors attending Arba Minch Blood Bank. Donors with blood group O are significantly more susceptible to asymptomatic malaria as compared to non-group-O donors. Further studies are recommended to assess the biological basis of association between $\mathrm{ABO} / \mathrm{Rh}$ blood group and malaria parasitemia.

\section{Abbreviations}

OR: Odds ratio

P. falciparum: Plasmodium falciparum 
P. vivax: Plasmodium vivax

RBC: $\quad$ Red blood cells

SEM: Standard error of the mean.

\section{Conflict of Interests}

The authors declared that no competing interests exist.

\section{Authors' Contributions}

Getaneh Alemu conceived and designed the project. Getaneh Alemu and Mohammedaman Mama performed the experiment, analyzed the data, and wrote the paper.

\section{Acknowledgments}

The authors thank Arba Minch Blood Bank laboratory technologists and nurses for their contribution during data collection and Arba Minch University for funding the research. The authors are grateful to ethical review boards of Arba Minch University and Arba Minch Blood Bank for giving ethical clearance. The authors regards also go to the study subjects for giving their consent to participate in the study.

\section{References}

[1] G. Garratty, W. Dzik, P. D. Issitt, D. M. Lublin, M. E. Reid, and T. Zelinski, "Terminology for blood group antigens and geneshistorical origins and guidelines in the new millennium," Transfusion, vol. 40, no. 4, pp. 477-489, 2000.

[2] M. Rahman and Y. R. Lodhi, "Frequency of ABO and Rhesus blood groups in blood donors in Punjab," Pakistan Journal of Medical Sciences, vol. 20, no. 4, pp. 315-318, 2004.

[3] P. A. Giri, S. Yadav, G. S. Parhar, and D. B. Phalke, "Frequency of $\mathrm{ABO}$ and rhesus blood groups: a study from a rural tertiary care teaching hospital in India," International Journal of Biological and Medical Research, vol. 2, no. 4, pp. 988-990, 2011.

[4] ISBT, Table of Blood Group Systems, International Society of Blood Transfusion (ISBT), 2008.

[5] H. Tadesse and K. Tadesse, "Assessing the association of severe malaria infection and $\mathrm{ABO}$ blood groups in northwestern Ethiopia," Journal of Vector Borne Diseases, vol. 50, no. 4, pp. 292-296, 2013.

[6] F.-I. Yamamoto, P. D. McNeill, and S.-I. Hakomori, "Genomic organization of human histo-blood group ABO genes," Glycobiology, vol. 5, no. 1, pp. 51-58, 1995.

[7] A. Mandefro, M. Kelel, and G. Wessel, "Association of Abo Blood Group and Rh Factor with malaria and some gastrointestinal infectious disease in a population of Adet and Merawi, Ethiopia," Global Journal of Biotechnology \& Biochemistry, vol. 9, no. 4, pp. 137-142, 2014.

[8] D. E. Reich, M. Cargili, S. Boik et al., "Linkage disequilibrium in the human genome," Nature, vol. 411, no. 6834, pp. 199-204, 2001.

[9] S. Chakraborty, "Heterozygosity and fixation index for ABO gene in Barak Valley populations," Notulae Scientia Biologicae, vol. 3, no. 1, pp. 7-11, 2011.

[10] S. Sidhu and L. S. Sidhu, "ABO blood group frequencies among the Sansis of Punjab," Collegium Antropologicum, vol. 4, no. 1, pp. 55-58, 1980.
[11] A. D. Kitchen and M. Elnageh, "Transmissible non-viral agents," in Transfusion Microbiology Practices, vol. 16, WHO Regional Publications, 1997.

[12] V. H. Talib and S. K. Khuana, Haematology for Students, CBS Publishers, New Delhi, India, 1996.

[13] M. S. Khan, F. Subhan, F. Tahir, B. M. Kazi, A. S. Dil, and S. Sultan, "Prevalence of blood groups and Rh factor in Bannu region," Pakistan Journal of Medical Sciences, vol. 43, no. 1, pp. 8-10, 2004.

[14] T. T. Epidi, C. D. Nwani, and N. P. Ugorji, "Prevalence of malaria in blood donors in Abakaliki metropolis, Nigeria," Scientific Research and Essays, vol. 3, no. 4, pp. 162-164, 2008.

[15] F. D. Otajevwo, "ABO blood groups association with malaria parasitaemia among residents in Warri, Delta State," Warri Journal of Science and Technology, vol. 4, no. 1, pp. 32-35, 1997.

[16] M. Sirina and O. Clement, "The prevalence of malaria parasitaemia and predisposition of ABO blood groups to Plasmodium falciparum malaria among blood donors at a Ghanaian Hospital," AU Journal of Technology, vol. 16, no. 4, pp. 255-260, 2013.

[17] P. C. Ilozumba and C. R. Uzozie, "Prevalence of malaria parasitaemia and its association with $\mathrm{ABO}$ Blood Group in Odoakpu Area of Onitsha South Local Government Area, Anambra State Nigeria," Nigerian Annals of Natural Sciences, vol. 8, no. 2, pp. 1-8, 2009.

[18] B. H. Oladeinde, R. Omoregie, E. O. Osakue, and T. O. Onaiwu, "Asymptomatic malaria among blood donors in benin city Nigeria," Iranian Journal of Parasitology, vol. 9, no. 3, pp. 415422, 2014.

[19] A. E. Yuzhalin and A. G. Kutikhin, "ABO and Rh blood groups in relation to ovarian, endometrial and cervical cancer risk among the population of south-east Siberia," Asian Pacific Journal of Cancer Prevention, vol. 13, no. 10, pp. 5091-5096, 2012.

[20] H. Wazirzai, A. Ashfaque, and J. W. Herzig, "Association of blood group A with increased risk of coronary heart disease in the Pakistani population," Pakistan Journal of Physiology, vol. 1, no. 2, pp. 1-3, 2005.

[21] N. C. Kumar, M. Nadimpalli, V. R. Vardhan, and S. D. Gopal, "Association of ABO blood groups with Chikungunya virus," Virology Journal, vol. 7, article 140, 2010.

[22] C. C. Blackwell, S. Dundas, V. S. James et al., "Blood group and susceptibility to disease caused by Escherichia coli O157," The Journal of Infectious Diseases, vol. 185, no. 3, pp. 393-396, 2002.

[23] B. H. Athreya and L. L. Coriell, "Relation of blood groups to infection I. A survey and review of data suggesting possible relationship between malaria and blood groups," American Journal of Epidemiology, vol. 88, no. 2, pp. 292-304, 1967.

[24] S. K. Singh, A. P. Singh, S. Pandey, S. S. Yazdani, C. E. Chitnis, and A. Sharma, "Definition of structural elements in Plasmodium vivax and P. knowlesi Duffy-binding domains necessary for erythrocyte invasion," Biochemical Journal, vol. 374, no. 1, pp. 193-198, 2003.

[25] A. O. Oche and M. Aminu, "The prevalence of malarial parasitaemia among blood donors in Ahmadu Bello University Teaching Hospital, Shika, Zaria, Nigeria," Nigerian Journal of Medicine, vol. 21, no. 4, pp. 445-449, 2012.

[26] D. E. Agbonlahor, F. I. Obi, O. Esumeh, A. A. Ajanaku, and E. O. Igumbor, "Association of $\mathrm{ABO}$ blood groups and malaria parasitaemia among students of Edo State University, Ekpoma, Nigeria," Journal of Medical Laboratory Science, vol. 4, no. 2, pp. 12-19, 1993. 
[27] R. P. Karyakarte and A. Damle, Medical Parasitology, Runabhan Books and Allied (P), New Delhi, India, 2003.

[28] L. S. Greene, "G6PD deficiency as protection against falciparum malaria: an epidemiologic critique of population and experimental studies," American Journal of Physical Anthropology, vol. 36, supplement 17, pp. 153-178, 1993.

[29] A. I. Alouch, "Sickle cell disease and malaria parasitaemia in a tropical setting," The Journal of Biological Chemistry, vol. 12, pp. 23-30, 1997.

[30] C. Ruwende and A. Hill, "Glucose-6-phosphate dehydrogenase deficiency and malaria," Journal of Molecular Medicine, vol. 76, no. 8, pp. 581-588, 1998.

[31] A. Astatkie, "Knowledge and practice of malaria prevention methods among residents of Arba Minch Town and Arba Minch Zuria District, Southern Ethiopia," Ethiopian Journal of Health Sciences, vol. 20, no. 3, pp. 185-193, 2010.

[32] M. Cheesbrough, Parasitological Tests. District Laboratory Practices in Tropical Countries, Cambridge University Press, Cambridge, UK, 2000.

[33] A. K. Owusu-Ofori, M. Betson, C. M. Parry, J. R. Stothard, and I. Bates, "Transfusion-transmitted malaria in Ghana," Clinical Infectious Diseases, vol. 56, no. 12, pp. 1735-1741, 2013.

[34] C. J. Uneke, O. Ogbu, and V. Nwojiji, "Potential risk of induced malaria by blood transfusion in South-Eastern Nigeria," McGill Journal of Medicine, vol. 9, no. 1, pp. 8-13, 2006.

[35] A. E. Mourant, A. C. Kopec, and K. Domaniewska-Sobczak, The Distribution of the Human Blood Groups and Other Polymorphisms, Oxford University Press, London, UK, 1976.

[36] P. Garg, S. Upadhyay, S. S. Chufal, Y. Hasan, and I. Tayal, "Prevalance of $\mathrm{ABO}$ and rhesus blood groups in blood donors: a study from a tertiary care teaching hospital of Kumaon region of Uttarakhand," Journal of Clinical and Diagnostic Research, vol. 8, no. 12, pp. 16-19, 2014.

[37] T. Zerihun, A. Degarege, and B. Erko, "Association of ABO blood group and Plasmodium falciparum malaria in Dore Bafeno Area, Southern Ethiopia," Asian Pacific Journal of Tropical Biomedicine, vol. 1, no. 4, pp. 289-294, 2011.

[38] F. Otajevwo, "Prevalence of malaria parasitaemia and its association with $\mathrm{ABO}$ blood grouping among students of Igbinedion University Okada, Nigeria," British Journal of Medicine and Medical Research, vol. 3, no. 4, pp. 1164-1177, 2013.

[39] M. S. Ali, A. Gader, M. Y. Kadaru, and M. S. Mustafa, "Screening blood donors for malaria parasite in Sudan," Ethiopian Journal of Health Development, vol. 18, no. 2, pp. 70-74, 2005. 


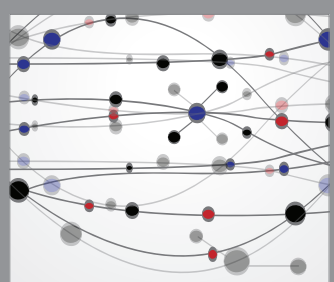

The Scientific World Journal
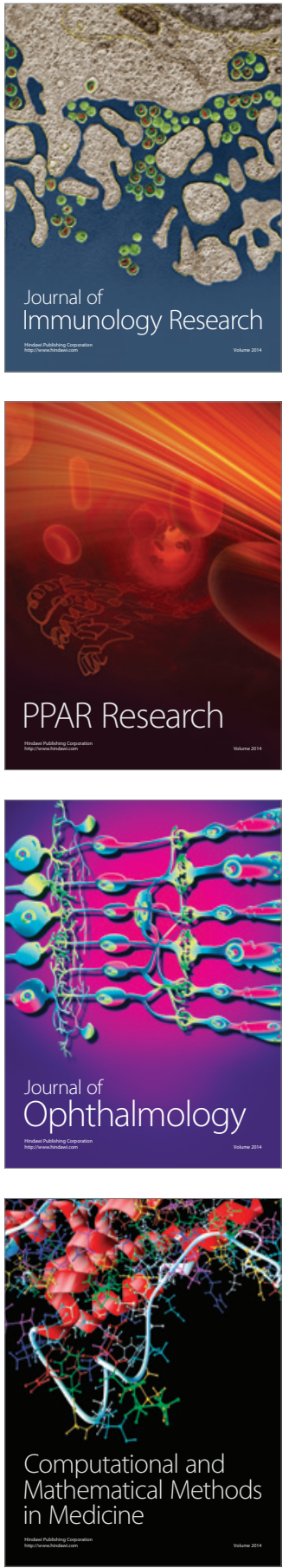

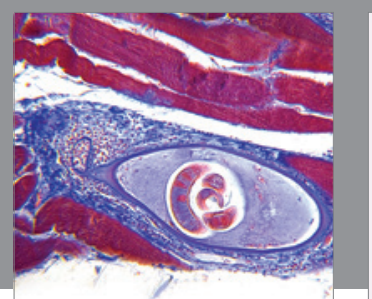

Gastroenterology Research and Practice

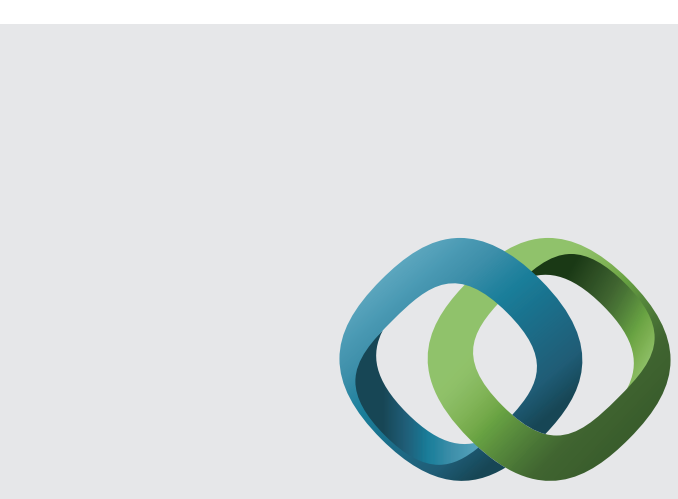

\section{Hindawi}

Submit your manuscripts at

http://www.hindawi.com
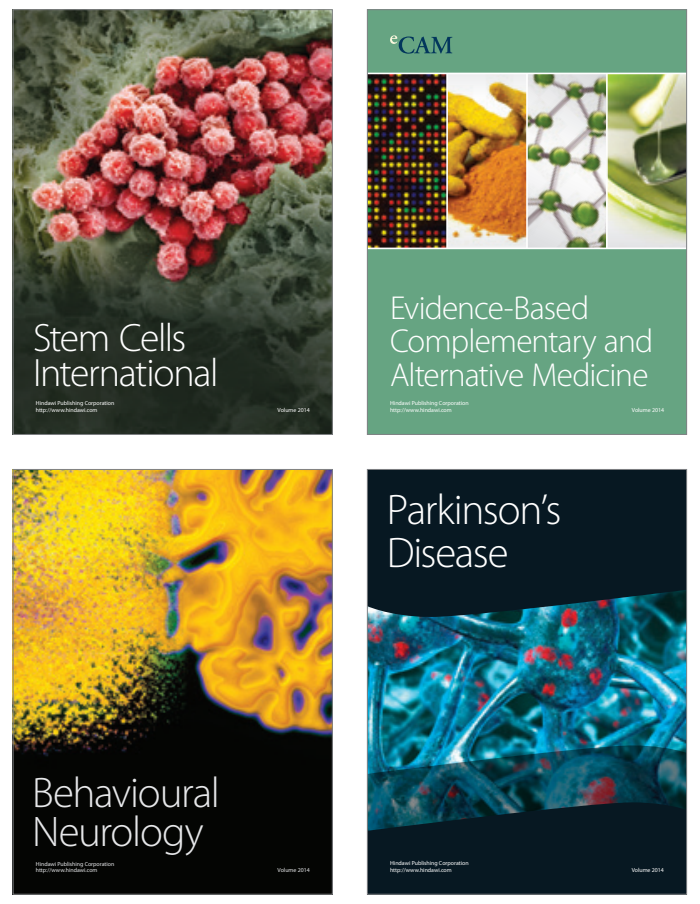
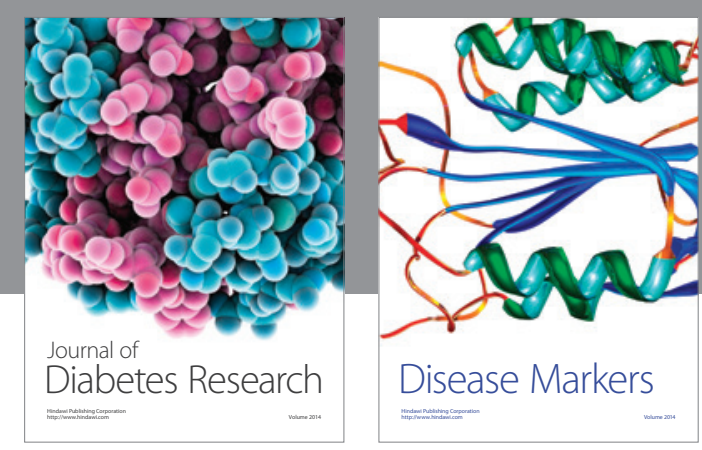

Disease Markers
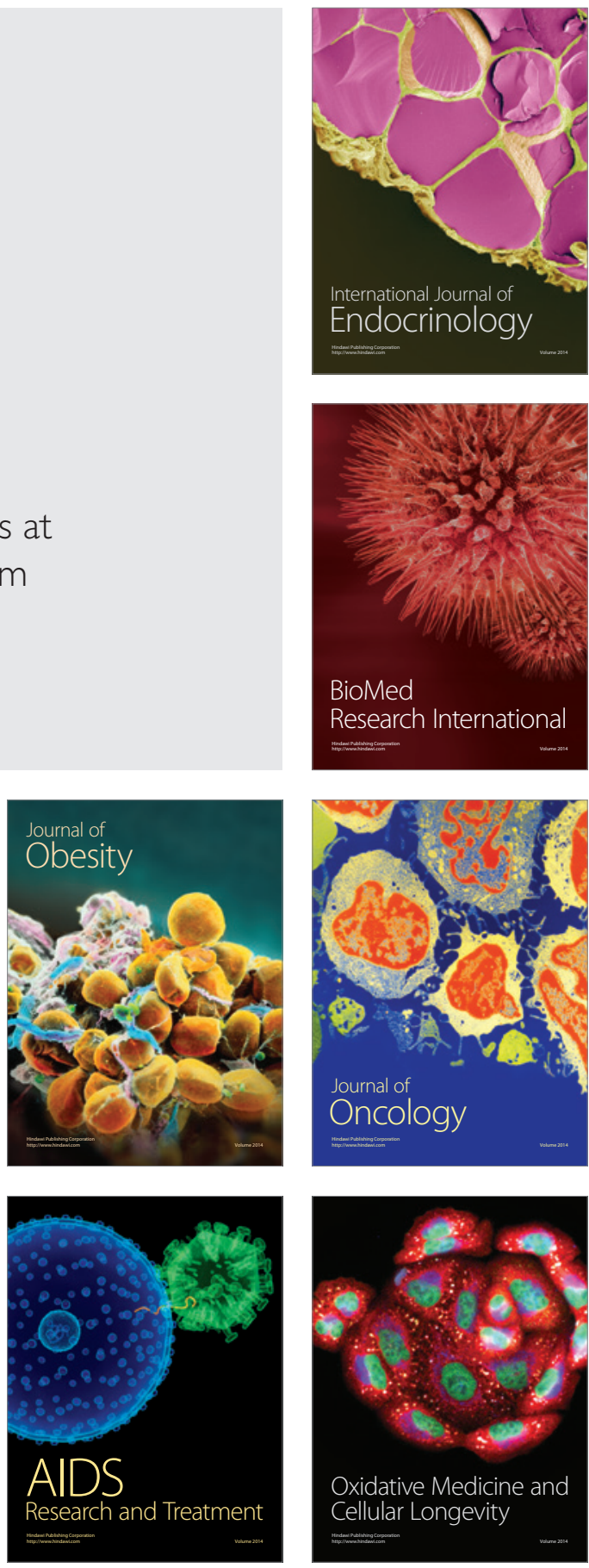